\title{
Exploitation of the European Research Projects Aiming to Achieve a Behavior Change for Energy Saving Through Innovative IT Solutions ${ }^{+}$
}

\author{
Hanna Launonen ${ }^{1}$, Ana Tisov $2, *$, Alessia Melasecche Germini ${ }^{3}$, Rosamaria Olivadese ${ }^{4}$, \\ Ksenia Koroleva 5, Maddalena Lukasik ${ }^{3}$, Anna Malamou 6, Dena Arabsolgar 7 , \\ Evangelos Zacharis ${ }^{8}$ and Anastasia Garbi ${ }^{6}$ \\ 1 VaasaETT, Oy Ab Ltd, Sörnäisten rantatie 29, 00500 Helsinki, Finland \\ 2 Huygen Engineers and Consultants, Urmonderbaan 22, gebouw 220, 6167 RD Sittard Geleen, \\ The Netherlands \\ 3 META Group, Avenue des Arts, 6 Bruxelles, Belgium \\ 4 DEMO Consultants BV, Delftechpark 10, 2628XH Delft, The Netherlands \\ 5 European Institute for Participatory Media, Pariser Platz 6, 10117 Berlin, Germany \\ 6 European Dynamics SA 209, Kifissias Av. \& Arkadiou Str., 15124 Maroussi, Athens, Greece \\ 7 Holonix Srl, Corso Italia, 8, 20821 Meda MB, Italy \\ 8 Hypertech SA, 32 Perikleous st., 15232 Halandri, Attica, Greece \\ * Correspondence: a.tisov@huygen.net \\ † Presented at the Sustainable Places 2019 (SP 2019), Sardinia, Italy, 5-7 June 2019. \\ Published: 24 July 2019
}

\begin{abstract}
Under H2020 program, the European Commission (EC) is investing in projects that aim to develop IT tools that are attractive for its users and therefore leading to a long-term behavior change for energy savings. Four of such funded projects are: BENEFFICE, enCOMPASS, MOBISTYLE and UtilitEE. To ensure exploitation and further uptake of the project results, EC provides Support Services for Exploitation of Research Results (SSERR). Through this support, a workshop was held at the Sustainable Places Conference 2019 to present the business value proposition of the above mentioned H2020 projects. This paper presents the outcomes of the workshop on how to pitch the research projects. Conclusive remarks were given to provide projects partners further recommendations on how to exploit the results to key actors (such as investors and business partners).
\end{abstract}

Keywords: behavioral change; customer engagement; energy-as-a-service; new business models; commercialization of results

\section{Introduction}

Citizens are increasingly requesting value for money: public money has to be well invested and the return on the investment must be effective. This is the challenge that every day, more and more, any Donor (including the European Union (EU) which is investing billions in Research activities) is facing. It is not new that the EU is encouraging research projects' partners to ensure that selected results are brought to the next stage.

Exploitation is integral part of the European research projects, nevertheless, during the projects duration the full potential of this accumulated knowledge, produced results is often not utilized. Therefore, to maximize the impact of European funding, the EC explicitly identifies the need for well elaborated project plans incorporating detailed exploitation strategies to define how these projects results will be implemented and what impact will have on the current market on a long run. That action plans are not just deliverables but actual plans dealing with real activities where partners commit themselves to implement the solutions, having identified resources and first operative steps. 
The workshop "How to achieve a BEHAVIORAL CHANGE for energy saving through innovative IT solutions" was organized as part of Sustainable Places event in Cagliari, Italy on 7 June 2019. It brought together four research projects co-funded by the European Commission under the call EE-07-2016-2017-Behavioral change toward energy efficiency through ICT and working towards the same aim. The four projects, namely:

- $\quad$ BENEFFICE-Energy Behavior Change driven by plug-and-play-and-forget ICT and Business Models focusing on complementary currency for Energy Efficiency for the Wider Population,

- enCOMPASS-Collaborative Recommendations and Adaptive Control for Personalized Energy Saving,

- MOBISTYLE-Motivating end-users behavioral change by combined ICT based tools and modular information services on energy use, indoor environment, health and lifestyle,

- UtilitEE-Utility Business Model Transformation through human-centric behavioral interventions and ICT tools for Energy Efficiency,

share common ground in the context of reaching behavioral change toward energy efficiency through ICT. However, the implementation and the key exploitable results vary.

As the research projects and EU co-funded innovation projects mature, one of the challenges that many of them face, is related to the commercialization of the end-product. In order to maximize the value added and impact of research projects, the Directorate-General for Research and Innovation offers on-demand services to interested projects-Support Services for Exploitation of Research Results (SSERR) (http://sserr.meta-group.com/SitePages/default.asp) [1]. Services are managed and delivered by META Group (www.meta-group.com).

Non technological bottlenecks (knowledge of the market, financial issues, regulatory environment, etc.) prevent a research result from making it to the end users; therefore, the SSERR provides support to bridge the gap between research results and the market by:

- raising awareness of exploitation possibilities;

- providing an opportunity to clarify issues, propose solutions and actions, and anticipate possible conflicts for a successful exploitation of research results;

- $\quad$ helping set roadmaps for the long-term sustainability of project results;

- creating value out of novel knowledge (creating revenues, improving skill set of an organization, setting a standard, improving applications for next grant).

After promising results from prior exploitation workshops with SSERR, the four projects engaged to a pitching service with the META Group to map the key exploitable results and steps forward.

This report will discuss the preparation process towards the pitching event, the project-specific outcomes and next steps going forwards.

\section{Method}

The process to prepare for the pitch was composed of several steps as described in Figure 1. After the initial alignment of the common aim for the pitching event, it was concluded that only three projects would pitch their product whereas BENEFFICE would take part but not produce a pitch at the current stage of development.

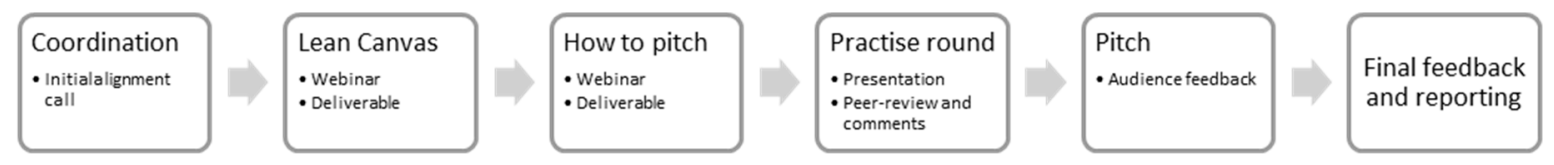

Figure 1. Steps towards the Pitching Workshop. 
Lean Canvas approach is proven to be powerful when exploring the commercialization potential of a product or service. For this reason, the group was introduced with the concept and asked to prepare one. This forced the projects to carefully observe their target customers, the market needs, how does each solution meet those needs, as well as the Unique Value Proposition; how and why their solution is different from the competitors. Based on the feedback received from Dr Alessia Melasecche Germini from META Group, projects were able to refine their strategies and prepare the actual pitch. To ensure the preparedness of the presentations, a preparation workshop was organized on the previous day where the speakers had the opportunity to hear comments and initial feedback on their presentations from their peers and do last minute adaptations. On the workshop day, each pitch received a good amount of questions and comments from the audience, of which some of them very challenging. Each pitch was assessed by the audience based on the clarity, level of interestingness and concept, and also by META Group through a final report and recommendations.

\section{Project-Specific Results}

The following sub-sections will describe the outcomes by project derived from the process, outlining the key points of each pitch and the next steps.

\subsection{BENEFFICE (http://www.beneffice.eu/)}

BENEFFICE aims to achieve improved energy efficiency by leveraging diverse tools that will enable consumers to understand their energy consumption and adopt Energy Efficiency behavior. In summary, it consists of the following tools:

(a) A hardware kit, that is easy to install and directly interconnected with the BENEFFICE system which captures the energy measurements at home. It is very affordable and is expected to attract the interest of consumers who want simple and effective solutions.

(b) A disaggregation engine that allows consumers to understand the devices and activities that consume the most energy to help them target them with specific actions.

(c) A recommendation engine that provides personalized and easy to understand and execute advice through tips, recommendations and challenges that address the specific identified wastage in the way that best matches the consumer profile/segment.

(d) The BENEFFICE mobile application that enables anytime, anyplace access to the actual energy consumption and relative recommendations and challenges to assist them in achieving greater energy savings.

(e) The $\mathrm{CO}_{2}$ credits stimulate the reduced energy use, and consequently reduced $\mathrm{CO}_{2}$ emissions, by rewarding the energy savings with $\mathrm{CO}_{2}$ digital coin.

BENEFFICE will engage with a wide range of consumer types and under a wide range of cases, conditions, profiles in Austria, France and Greece during its upcoming piloting phase where valuable insights on the opinion of early adopters of BENEFFICE will be obtained.

In the long term, target customers are all individual households in Europe that wish to win money as reward to their energy efficient behavior. The combined services mentioned above will attract and engage consumers in Energy Efficient actions and will ensure the wide deployment and applicability of BENEFFICE.

\section{2. enCOMPASS (http://www.encompass-project.eu/)}

The enCOMPASS pitch presented an overview of the enCOMPASS platform, with a focus on how the service intends to bring transparency and awareness to energy use. Today's energy consumers are frequently unaware of how their energy consumption effects their energy bill and their ecological footprint. In addition, energy consumers are often unsure of what they themselves can do to lower their own energy consumption. Meanwhile, municipal utilities are interested in developing innovative environmentally focused services, which will allow them to distinguish themselves from competition and also respond to the new service demands of customers. 
The enCOMPASS solution seeks to take advantage of these opportunities by designing a platform for municipal utilities to offer to their customer base. This service visually reports data collected from the end user's smart meter and home appliances to their mobile device, making previously ambiguous energy use accessible and understandable. It not only uses standard bar charts, but also interactive visualizations displaying the impact of the energy savings in monetary and environmental terms (cf. Figure 2a). The mobile application then provides personal, context aware, actionable recommendations that assist the end user with saving energy (cf. Figure $2 b$ ). In addition to receiving these tips, users are also encouraged to lower their energy consumption through gamified incentives, such as goal setting and goal monitoring features (cf. Figure 2c). A recently conducted market comparison shows that regarding these features enCOMPASS clearly distinguishes itself from competition.

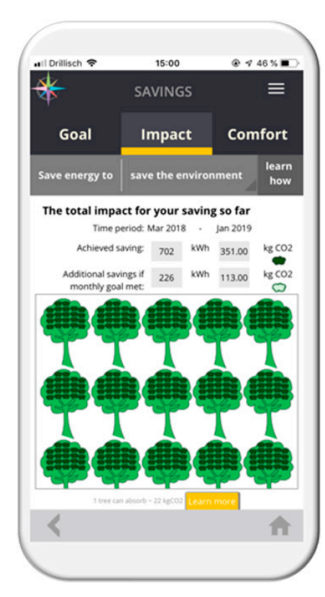

(a)

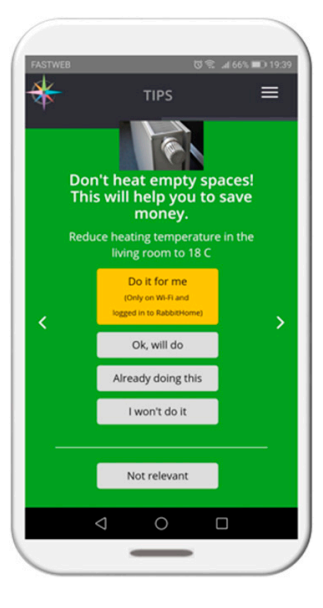

(b)

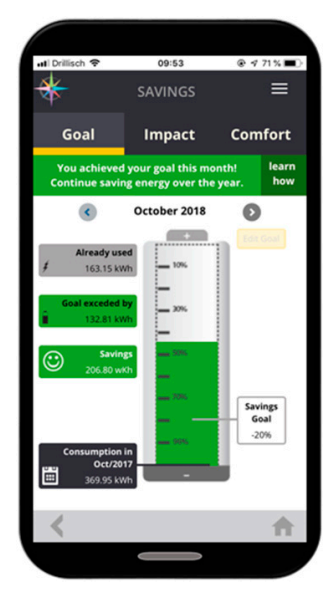

(c)

Figure 2. Examples of enCOMPASS pages: (a) environmental impact visualization page; (b) tips page;

(c) goal monitoring page.

Currently, the enCOMPASS platform is undergoing three trails with pilots in Germany, Switzerland and Greece, in households, schools and public buildings. Early results indicate that for example in Switzerland the platform is successful in reducing household user energy consumption on average by $5.81 \%$ as opposed to the control group which increased the consumption by $1.33 \%$ [2]. Additionally, the application leads to the increase in energy related knowledge already after 4 months of using the application [2]. In order to bring the enCOMPASS project out of development and into the market, an initial investment of $€ 1,000,000$ is needed. A majority of this investment will go towards making the necessary product engineering and evolution changes, based on insights gleaned after nearly one year of pilot testing and feedback. This investment will also provide needed trademarks and patents and also pay for server costs and API integration. Finally, the remainder of the investment will cover strategic marketing costs.

The feedback received after the pitching session was very valuable and allowed to improve the unique value proposition of enCOMPASS further, as well as assign more budget to marketing costs in order to be able to successfully bring the application to the market.

\subsection{MOBISTYLE (https://www.mobistyle-project.eu/)}

To answer different stakeholders needs, MOBISTYLE develops different ICT solutions for the identified stakeholder groups [3]. This creates a first challenge for MOBISTYLE in terms of exploitation. The main solution to be exploited as the MOBISTYLE platform is made of 5 different IT tools: 
1. a customizable dashboard for non-residential buildings users (customers as hotels and university offices);

2. a gamified mobile app for residential users (to be sold by utilities or by social housing organizations to householders);

3. a dashboard to visualize dynamics conditions indoor for private offices,

4. a data visualization tool for experts' calculations and analysis,

5. an Open Users Platform able to give MOBISTYLE aggregated data to 3rd party developers.

The pitch was structured in a story telling way, addressing the MOBISTYLE customer via his/her user journey. The aim was to show the potential customer which would be for him/her the added value of using the MOBISTYLE solutions. The MOBISTYLE Platform is able to collect data coming from different sources (energy consumption smart meters, Indoor Environmental Quality (IEQ) sensor and health wearables) in a single environment and to transform these data into quick, up to date and easy to be understood information, everything in one application. Data are also correlated with tips and tricks on how to raise personal indoor comfort and save on energy bills by improving the energy usage.

Two segments of customers have been identified: a) Customers interested in engaging more with their client, for example housing associations, real estate owners, tertiary companies, service and energy providers, and b) Customers interested in data such as 3rd parties developers, data providers, manufactures, service and energy providers.

The features provided by the MOBISTYLE Platform are currently at prototype level and are being tested in several study cases in Europe (Italy, Slovenia, Netherlands, Denmark and Poland).

The team is composed by software developers to support you on technical level in collecting, analyzing and disclosing the information to your client; anthropologists specialized on user behavior; energy and data experts.

After the pitch, valuable feedbacks were received that will be used to improve the initially developed exploitation strategy to answer better the real market needs. First, the possibility to combine different kind of data types is recognized as of high value, empowering the platform and the single tools. Second, the possibility to Open the Data to externals in an aggregated and anonymized way, is recognized as high potential. To achieve these two added values, MOBISTYLE needs to achieve the following:

1) Access to a significant amount of buildings (and users) data

2) Aggregation methodology allowing joint assessment of the different types of data to provide Innovative Key Performance Indicators (KPIs) giving insights in energy, IEQ and personal health.

Having five completely different demonstration cases could help understanding the best differentiating approach to exploitation. The five demonstration cases will be involved further in the exploitation process, analyzing one by one the dimensions of the target market, and the interest raised by the entire MOBISTYLE platform and the single tools.

\subsection{UtilitEE(https://www.utilitee.eu/)}

For UtilitEE, as the starting point, the market problem to address was two-fold:

- "A Digital \& Data Driven World" - a future where smart devices in the world of Internet-ofThings, collect energy and performance data that offers knowledge-based, value-added energy services to customers.

- "Out of touch"-a future where energy retailers lose touch with their customers who are constantly seeking cost effective and innovative service provision and not just a volume of kWhs.

Faced with these expectations, the UtilitEE solution is aiming to fulfil the requirements placed by both the energy retailers and the end-users. Firstly, UtilitEE fosters continuous consumer engagement through a user-driven energy behavior change framework that addresses consumers with intuitive, actionable messages through the developed ICT tool. Secondly, the novel utility business models and roles defined during the project enable a deep transformation of current business-as-usual utility practices and enhance their viability in evolving market conditions. 
The UtilitEE solution is not brought to the market hastily; during the three-year research, it defines, experiments with and validates the business models for future-looking retailers. As part of the team, there are five energy retailers across Europe running pilots with both residential and commercial building sites to validate the concept. The mentioned developed business models fall into two categories:

- $\quad$ Retailer As ESCO

- Energy efficiency audits towards near zero energy building

- Comfort preserving energy efficiency

- Retailer As Aggregator

- Supply-demand and imbalance management

- Community VPPs

- DSO costs minimization

- Dynamic retailer pricing schemas

The UtilitEE solution is not brought to the market hastily; during the three-year research, it defines, experiments with and validates the business models for future-looking retailers. As part of the team, there are five energy retailers across Europe - MIWenergía, Spain; Mytilineos, Greece; Sorea, France; SWT, Germany and Tauron, Poland - running pilots with both residential and commercial building sites to validate the concept. In the development work a range of professionals from variety of organizations are participating, such as technology developers, solution providers, think tanks and research organizations:

- Grupo ETRA I+D, Spain

- HYPERTECH, Greece

- $\quad$ Suite5, Cyprus

- Solintel, Spain

- University of Basel, Switzerland

- VaasaETT, Finland

For the commercialization of the solution, the team was asking for an investment for total estimated cost of the $1 \mathrm{M} €$, for $40 \%$ of shares. For this purpose, they were seeking investors across EU and more specifically focusing on more mature and Internet-of-Things oriented "smart" markets such as UK, Germany, Denmark and Sweden.

Large part of the concerns raised by the audience was related to the privacy issues, personal data management and ownership. These aspects can be a barrier for market roll-out if not anticipated and resolved. Additionally, communicating the unique value proposition very clearly to justify why UtilitEE solution is appealing or a better choice than the competitors to the target group is key when pitching and winning the audience.

\section{Conclusive Remarks}

The research that is prioritized and funded today under $\mathrm{H} 2020$ will have a decisive impact on the future of our societies and our planet. We are facing massive ecological, social and economic challenges. It is certainly no time for "business as usual", and radical behavioral change is needed for society to address these challenges. Research and technology have a crucial role to play but must, especially when publicly funded, benefit the community as a whole and this exactly where BENEFFICE, enCOMPASS, MOBISTYLE and UTILITEE play a crucial role.

The goal of the workshop "How to achieve a BEHAVIORAL CHANGE for energy saving through innovative IT solutions" was to brainstorm and fine tune joint win-win strategies and actions to overcome the natural tendency of European research projects to work in silos. Participants and attendees were enthusiastic about the opportunity to collaborate, share ideas and strategies with the aim that results achieved/to be achieved will have a greater Impact on the community and the market beyond their own individual fields of application. What is important for the attendees, is that their 
efforts put in the results research would not be lost after the granting period but will be fruitful for the society's and environment's future.

Market and customer analysis as well as end users' involvement are some of the potential points of contact among the four projects, synergies could be developed, joint activities could be carried on and/or results could be shared. This would help in terms of leveraging on the different partnerships and would represent a clear benefit in terms of approaching a bigger mass of relevant stakeholders and in terms of time and financial savings. The same applies to specific technical issues that may arise during the research/development phase and could have been already faced/overcome by other projects' partners. In this direction Coordinators should act as "door openers" to interested/involved project partners. On top, projects can reach a wider audience to justify the efforts that are put, and the investments made if collaborating on Communication and Dissemination activities as well. Research that will make Europe (and the world) an environmentally sustainable and healthier place to live, needs joint efforts and focused commitment, without losing the momentum. The positive attitude of this workshop, the brainstorming of attendees made in this occasion, the determination that pool everyone, will give good results and potentially inspiration to other projects.

Funding: The projects have received funding from the European Union's Horizon 2020 research and innovation programme under the following Grant Agreements: No. 768774 (BENEFFICE), No. 723059 (enCOMPASS) No. 723032 (MOBISTYLE), No. 768600 (UTILITEE).

Conflicts of Interest: The authors declare no conflict of interest. The sole responsibility for the content lies with the project's consortium. It does not necessarily reflect the opinion of the European Communities. The European Commission is not responsible for any use that may be made of the information contained therein.

\section{References}

1. Melasecche Germini, A.; Nunziangeli, L. Recherche et Innovation: Comment avoir plus d'impact? In Management and Governance of the University of the Future; University of Social Sciences: Krakow, Poland, 2018; pp. 211-225, ISBN 978-83-64971-47-1.

2. Koroleva, K.; Mehlenhorst, M.; Novak, J.; Herrera Gonzalez, S.L.; Fraternali, P.; Emilio-Rizzoli, A. Designing a holistic socio-technical behavior change systems for energy saving. Energy Informatics accepted for publication.

3. Tisov, A.; Podjed, D.; D’Oca, S.; Vetršek, J.; Willems, E.; Veld, P.O. People-Centred Approach for ICT Tools Supporting Energy Efficient and Healthy Behaviour in Buildings. Proceedings 2017, 1, 675, doi:10.3390/proceedings1070675

(C) 2019 by the authors. Licensee MDPI, Basel, Switzerland. This article is an open access article distributed under the terms and conditions of the Creative Commons Attribution (CC BY) license (http://creativecommons.org/licenses/by/4.0/). 